\title{
DE LAS ESCUELAS DE PÁRVULOS A LOS JARDINES DE NIÑOS. CONSTRUCCIÓN DE LA CULTURA ESCOLAR EN LA EDUCACIÓN PREESCOLAR DEL ESTADO DE MÉXICO, 1881-1926,
}

por Élida Lucila Campos Alba. México, El Colegio Mexiquense, 2013, 442 pp. ISBN: 978-607-7761-50-1

México cuenta con una copiosa producción sobre historia de la educación. Si los primeros trabajos académicos contemplaron la educación en su acepción más tradicional y vinculada únicamente al ámbito escolar, en los últimos años los historiadores, influidos por los debates culturalistas que ocurrían en la pedagogía, en la etnografía, y la sociología de la educación, fueron flexibilizando la definición de la educación, dotándola de un marco conceptual mucho más complejo y enriquecedor. De tal forma, la educación apareció como un conjunto de procesos ocurridos dentro y fuera de la escuela, es decir como un campo no necesariamente vinculado a ésta última.

En la historiografía de la educación mexicana posterior a la década de los años noventa, paulatinamente comenzaron a aparecer conceptos como «saberes», "prácticas escolares» o "cultura escolar», e incluso el estudio de los «actores» de los procesos educativos se amplió, abriendo un amplio y heterogéneo abanico de sujetos partícipes de los procesos educativos: maestras y maestros, niños, inspectores, médicos, artistas. El libro De las escuelas de párvulos a los jardines de niños. Construcción de la cultura escolar en la educación preescolar del Estado de México, 1881-1926, de Élida Lucila Campos Alba, busca precisamente inscribirse en esta nueva tradición historiográfica y a partir de interrogantes basados en ciertas categorías analíticas sobre temáticas que no habían sido tratadas anteriormente. De tal modo, Campos Alba reconstruye la historia de cómo se instalaron las primeras escuelas de párvulos en las últimas décadas del siglo XIX en el Estado de México y cómo fue el proceso a través del cual se convirtieron en jardines de niños hacia 1926. 
En la primera parte del libro la autora elabora una interesante síntesis sobre el surgimiento de las instituciones de educación preescolar en algunos países europeos y en Estados Unidos, así como de los principales postulados que elaboró Federico Froebel. Resalta cómo las primeras guarderías en Europa surgieron a partir de las instituciones de beneficencia y con un claro fin de ayuda social a las madres trabajadoras. Es destacable el esfuerzo de la autora para rastrear los caminos y medios por los que el pensamiento de Friedrich Froebel llegó a México, el modo en que sus propuestas fueron en cierta medida «nacionalizadas», «interpretadas a la mexicana y a la mexiquense», es decir, como se apropiaron de la lectura de Froebel los educadores mexicanos, que en un inicio pertenecían a una élite intelectual y luego por las maestras frente al grupo que años después atendería a los niños de kindergarten.

En este libro se demuestra que fue el sistema de enseñanza de Froebel el que se adoptaría en México por varias décadas, incluso hasta entrado el siglo XX. Los educadores y educadoras mexicanas se nutrirían de ideas pedagógicas de pensadores españoles también. En tanto se revaloran los grandes nombres de la pedagogía europea, el libro atiende a la necesidad de rescatar la labor de los principales ideólogos del kindergarten mexicano: Justo Sierra, como el hombre que consolida la educación parvularia en las políticas educativas mexicanas, Estefanía Castañeda, Rosaura Zapata, Laura Méndez de Cuenca y Bertha von Glümer.

El tradicional vínculo entre mujer y maternidad y las mujeres como los actores «naturalmente» destinados a atención a la infancia, se retoman como un elemento de análisis, mostrando cómo los interesados en establecer el kindergarten en México invitan y capacitan a mujeres mexicanas para trabajar en estas escuelas, lo cual entra en obligada tensión con la idea tradicional de que las mujeres debían mantenerse en el ámbito del hogar. Sierra hace que sean las mujeres las que organicen esta etapa educativa a partir de principios liberales que excluyeran el dogmatismo religioso, el romanticismo y la mística. Las propuestas de estas maestras serían determinantes por varias décadas y marcarían en gran medida su identidad profesional.

El libro va mostrando cómo la enseñanza preescolar se convierte en un espacio educativo particular, separado de la educación primaria, a la que la autora señala como una cultura escolar propia y diferenciada. Ahora bien, 
en tanto uno de los ejes vertebradores del libro es el estudio de la cultura escolar de los jardines de niños, se atiende a las teorías, los conocimientos y habilidades promovidos por los planes curriculares, las reformas educativas, las rutinas escolares, los espacios escolares y sus objetos, la graduación por edad, las actitudes y los valores dominantes y los discursos escritos que circulan en torno a la educación de la primera infancia. Sin embargo, es posible que al terminar este libro, algunos lectores puedan sentir que muchos otros aspectos de la cultura escolar han quedado sin cubrir. Esto se debe probablemente a la dificultad propia de las fuentes primarias. Los diversos rituales y actos preformativos desarrollados al interior de los jardines de niños, las formas en que los niños-alumnos formaron parte esencial de la construcción de la cultura escolar, desarrollaron identidades y dotaron de significados a la escuela, quedan en suspenso.

El texto de Campos Alba abre muchas ventanas para reflexionar sobre la escolarización de la primera infancia. La autora señala desde un inicio el espacio historiográfico en el que inscribe su trabajo: la nueva historia cultural de la educación. Thomas S. Popkevitz, Barry M. Franklin y Miguel A. Pereyra hablaron hace ya algunos años de que la historia cultural de la educación se distinguía por su "preocupación por el conocimiento como un campo de prácticas culturales y de reproducción cultural», y enfatizaron en que este campo de especialización debería hablar de «cómo las ideas construyen, configuran, coordinan y construyen las prácticas sociales, a través de las cuales «razonan» los individuos sobre su participación y su identidad». ${ }^{1}$ En ese sentido, es necesario mencionar que los niños como individuos quedan desdibujados en este libro y no aparecen como agentes capaces de razonar, configurar, construir o reproducir prácticas sociales. La autora sostiene que los alumnos de los jardines de niños «son importantes, puesto que sostenemos que existe una relación directa entre la representación social de la infancia, específicamente de la edad correspondiente, y la creación y consolidación de una institución educativa específica, en tanto que los docentes son vitales». ${ }^{2}$ Es decir, aunque se menciona la relevancia

\footnotetext{
1 Thomas S. Popkewitz, Barry M. Franklin y Miguel A. Pereyra, «Prefacio», en Historia cultural y educación: ensayos críticos sobre conocimiento y escolarización, comps. Th. S. Popkewitz, B. M. Franklin y M. A. Pereyra (Barcelona: Pomares, 2003), 9-10.

2 Élida Lucila Campos Alba, De las escuelas de párvulos a los jardines de niños: construcción de la cultura escolar en la educación preescolar del Estado de México, 1881-1926 (México: El Colegio Mexiquense, 2013), 27.
} 
del niño, este libro vuelve a privilegiar a los docentes y los encargados de las políticas educativas como el centro neurálgico del proceso educativo en los jardines de niños. En ese sentido, el texto invita a plantear un interrogante: ¿valdría la pena ubicar a los niños-alumnos en el mismo nivel de trascendencia que los docentes? La respuesta podría ser afirmativa si partimos de la preocupación de buscar construir nuevas formas discursivas sobre el pasado de la educación, y de la idea de que, al final de cuenta, los niños son indiscutiblemente el objetivo final de los discursos y las prácticas educativas en el kindergarten.

Atinadamente, en el libro se reconoce que no se puede hablar unívocamente sobre «la cultura escolar», sino que habría que hablar de «culturas escolares» para aludir a un fenómeno «complejo y multidimensional». Sin embargo este mismo criterio no se utiliza para hablar de «la representación social de la infancia» que siempre aparece en singular. En el libro se insiste en una sola representación de la infancia que permearía a la sociedad mexicana entera. De ese modo se pierde el reconocimiento a la diversidad de infancias y de representaciones. En los siglos XIX y XX no existió una sola representación (el mismo concepto imposibilitaría tal cosa); las representaciones de la infancia entre 1881 y 1926 fueron múltiples y dependieron de las variadas producciones culturales y actores que las generaron. Coexistieron representaciones del niño como escolar simultáneamente a las del niño como trabajador, como ciudadano o como sujeto a curar y sanar. Las representaciones sobre la infancia que tuvieron ciertos grupos indígenas estaban completamente alejadas que las que sostenían los médicos porfiristas o las profesoras del kindergarten. De tal forma, en el mismo sentido que se subraya la necesidad de pensar la cultura escolar en plural, es perentorio pensar a la infancia y sus representaciones en plural.

En este texto se atiende y analiza con detenimiento y precisión la legislación y se muestra el progresivo aumento de la importancia del kindergarten en la educación mexicana. De las escuelas de amigas, pasando por las guarderías, la educación preescolar se convertirá precisamente en la transición del mundo del hogar a la educación primaria. En ese tránsito, las escuelas de párvulos se convierten en laboratorios para que practiquen quienes estudian para docentes, es por ello que varias de estas escuelas se construyen como anexos a las escuelas normales. Es sólo hasta la llegada del siglo XX que las escuelas de párvulos públicas se independizan y es posible encontrarlas alejadas de los edificios de educación normal. La introducción 
de la pedagogía froebeliana en el Estado de México, señala la autora, inicia entonces como un proceso autodidacta, y pasa luego a ser un sistema trabajado en las escuelas normales desde una mirada científica y academicista.

El largo preámbulo sobre la educación preescolar ubica al lector en las discusiones generales del contexto histórico de finales del siglo XIX y le permite a la autora pasar de lleno al estudio el caso específico que le ocupa: la educación preescolar en el Estado de México. Los jardines de niños se enfrentarían no sólo ante las limitantes económicas y políticas del estado mexicano y un notorio desprecio de los encargados de las políticas educativas hacia la primera infancia, sino también con la falta de interés de las familias mexicanas, que no veían cuál era la utilidad de esta educación, aunque en el caso mexicano, quienes asistirían inicialmente al kindergarten serían los niños hijos de familias pudientes y no los de las madres trabajadoras, como sucedía en Europa. En México, como señala la autora, el kindergarten era un lujo.

El texto es rico en imágenes y éstas trasladan al lector a la época en cuestión. Sin embargo, las imágenes son utilizadas para ilustrar el libro y no como fuentes históricas que ofrecen posibilidades analíticas de enorme riqueza. En tanto la autora atiende novedosamente al estudio de la cultura material escolar, al mobiliario específico que va a demandar la educación preescolar: mesas y sillas pequeñas, que debían ser sólidas pero transportables, por eso ligeras, que debían facilitar la individualidad del niño; las fotos ofrecen al lector información muy relevante sobre este tema pero que debe intuir por él mismo. A pesar de la calidad de impresión, en las fotos pueden observarse láminas y retratos en los muros escolares, imágenes dentro de las imágenes que evidencian la construcción de un imaginario visual para la infancia que fue fundamental en tanto aludió no sólo a la construcción de discursos científicos para la infancia, sino también a discursos de ciudadanía y de producción de modelos de sensibilidad nacional.

Las imágenes del aula que aparecen en las fotos, con un análisis detallado, mostrarían la importancia de la imagen como herramienta didáctica, como bien lo ha estudiado Sandra Szir para el caso argentino, como herramientas de transmisión del conocimiento, "de estímulo de la memoria y sentimientos de amor a la nación». ${ }^{3}$ El sistema Froebel planteó

${ }^{3}$ Sandra M. Szir, Infancia y cultura visual los periódicos ilustrados para niños (1880-1910), (Buenos Aires: Miño y Dávila, 2006), 84. 
incluso la observación de mapas y planos; es por eso que en un esquema del libro de Campos Alba aparece un inventario de las escuelas de párvulos en el cual se mencionan una colección de mapas de historia natural, doce cuadros representando industrias, cuatro cartas de retratos de héroes y un mapa de geografía física, perla informativa que no se examina y que habla del valor del recurso icónico y del uso y la importancia de la cultura visual en la educación de los niños pequeños.

Este libro no sólo permite conocer cómo se construyó la cultura escolar en la educación preescolar en el Estado de México, sino que motiva constantemente al lector a reflexionar y sugiere nuevos caminos para investigaciones sobre la historia de la educación de la primera infancia. No es exagerado afirmar que será una referencia ineludible para todos aquellos interesados en la educación de la primera infancia en México en el Porfiriato y los inicios del México posrevolucionario.

Susana Sosenski

IIH-Universidad Nacional Autónoma de México

sosenski@unam.mx 